\title{
Computed tomographic perfusion imaging for the prediction of response and survival to transarterial chemoembolization of hepatocellular carcinoma
}

\author{
Peter Popovic ${ }^{1}$, Ana Leban², Klara Kregar ${ }^{3}$, Manca Garbajs ${ }^{1}$, Rok Dezman¹, Matjaz Bunc ${ }^{4}$ \\ ${ }^{1}$ Clinical Institute of Radiology, University Medical Centre, Ljubljana, Slovenia \\ ${ }^{2}$ General Hospital Dr. Franca Derganca, Šempeter pri Gorici, Slovenia \\ ${ }^{3}$ General Hospital Jesenice, Jesenice, Slovenia \\ ${ }^{4}$ Department of Cardiology, University Medical Centre, Ljubljana, Slovenia
}

Radiol Oncol 2018; 52(1): 14-22.

Received 11 September 2017

Accepted 15 October 2017

Correspondence to: Assist. Prof. Peter Popovič, M.D., Ph.D., Clinical Institute of Radiology, University Medical Centre Ljubljana, Zaloška cesta 7, 1525 Ljubljana, Slovenia. E-mail: peter.popovic@kclj.si

Disclosure: No potential conflicts of interest were disclosed.

Background. The purpose of this retrospective cohort study was to evaluate the clinical value of computed tomographic perfusion imaging (CTPI) parameters in predicting the response to treatment and overall survival in patients with hepatocellular carcinoma (HCC) treated with drug-eluting beads transarterial chemoembolization (DEBTACE). Patients and methods. Between December 2010 and January 2013 eighteen patients (17 men, 1 woman; mean age $69 \pm 5.8$ years) with intermediate stage HCC underwent CTPI of the liver prior to treatment with DEBTACE. Treatment response was evaluated on follow-up imaging according to modified Response Evaluation Criteria in Solid Tumors. Pre-treatment CTPI parameters were compared between patients with complete response and partial response with a Student t-test. We compared survival times with Kaplan-Meier method.

Results. CTPI parameters of patients with complete response and others did not show statistical significant difference. The mean survival time was $25.4 \pm 3.2$ months (95\%; Cl: 18.7-32.1). Survival was statistically significantly longer in patients with hepatic blood flow (BF) lower than $50.44 \mathrm{ml} / 100 \mathrm{ml} / \mathrm{min}(p=0.033)$, hepatic blood volume (BV) lower than $13.32 \mathrm{ml} / 100 \mathrm{ml}(p=0.028)$ and time to peak (TP) longer than $19.035 \mathrm{~s}(p=0.015)$.

Conclusions. CTPI enables prediction of survival in patients with intermediate stage HCC, treated with DEBTACE based on the pre-treatment values of $\mathrm{BF}, \mathrm{BV}$ and TTP perfusion parameters. $\mathrm{CT}$ perfusion imaging can't be used to predict treatment response to DEBTACE.

Key words: hepatocellular carcinoma; computed tomography perfusion imaging; drug-eluting beads transarterial chemoembolization; response to treatment; survival

\section{Introduction}

Hepatocellular carcinoma (HCC) is the sixth most common cancer and the third most common cause of cancer mortality in the world. ${ }^{1}$ Patients with $\mathrm{HCC}$ are divided into five stages by the Barcelona Clinic Liver Cancer (BCLC) staging system according to pre-established prognostic variables. Those classified as intermediate or BCLC B stage present a mean 2-year survival of $49 \%$. Transarterial chemoembolization (TACE) is the standard treatment for such patients. ${ }^{1,2}$ Lately a new embolization agent called drug-eluting bead (DEB) has been introduced and several clinical studies have confirmed the benefits of DEBTACE with respect to 
improved tumor response, reduced adverse effects and improved survival. ${ }^{2-8}$

The European Association for the Study of Liver (EASL) has proposed to assess response to locoregional treatments by assessing the decrease in viable tumor volume, seen as a decrease in contrast-enhancing areas at conventional contrastenhanced computed tomography (CT) or magnetic resonance imaging (MRI) (modified Response Evaluation Criteria in Solid Tumors (mRECIST)). ${ }^{1,9}$ The number of treatment sessions with DEBTACE depends on the response of the tumor. As the therapy may be repeated and interchangeably applied, early assessment of treatment response is crucial. Early prediction of treatment response makes it possible to prevent unnecessary side effects and modify treatment plan or replace it with other more effective treatment modalities before tumor progression. Due to heterogeneity of the BCLC B stage patient population survival rates are variable and scattered across the literature. , $^{13-6,10-12}$ Therefore, not all patients with intermediate stage HCC will derive similar benefit from TACE. Some may benefit from other treatment options which are currently approved or being explored. These include different TACE modalities, such as selective TACE or DEBTACE, transarterial radioembolization (TARE), combined approaches with radiofrequency ablation (RFA) or sorafenib. ${ }^{1-4,13}$

Current prognostic factors for the prediction of treatment response and survival in patients treated with TACE such as clinical performance, status of patient, number and size of tumors, presence of macrovascular invasion, extrahepatic spread and grade of hepatic damage are mainly based on clinical assessment and are included in BCLC classification. ${ }^{1,13}$ However, the malignant nature of the tumor as well as other characteristics are not generally considered. Apart from well-known clinical factors related to tumor stage and liver function, remarkably few data are available upon other measurable predictive or prognostic factors for TACE treatment response and survival in intermediate stage HCC. Thus, careful selection of patients likely to respond and benefit from TACE using a noninvasive imaging biomarker seems important. ${ }^{13,14}$

Functional imaging techniques are technical improvement of conventional morphological techniques that can provide both qualitative and quantitative information on tumors. ${ }^{15-17}$ Perfusion parameters are therefore theoretically good candidates for the evaluation of microscopic vascular differences between lesions with different patho- logical grade and for the assessment of treatment response, especially after chemoembolization, or during treatments with anti-angiogenic drugs. ${ }^{18-26}$

Computed tomographic perfusion imaging (CTPI) is a dynamic, contrast-enhanced, minimally invasive functional radiologic imaging technique. It allows for an objective, quantitative evaluation of tissue perfusion. ${ }^{16}$ The basis for the use of CTPI in oncology is that the microvascular changes in angiogenesis are reflected by increased tumor vascularization in vivo..$^{18}$ High tumor angiogenesis activity is associated with distant metastases and is an adverse prognostic factor in cancers. ${ }^{27,28}$ We can identify the degree of angiogenesis in tumors with invasive histologic biomarkers such as microvessel density (MVD) and vascular endothelial growth factor (VEGF). Many studies have shown a direct correlation between these invasive histologic biomarkers and tumor CTPI parameters. ${ }^{15,20,29-31}$

The purpose of this retrospective cohort study was to estimate the clinical value of CTPI parameters in predicting the response and survival to DEBTACE of patients with intermediate stage HCC.

\section{Patients and methods}

This retrospective cohort study took place at Clinical Institute of Radiology (CIR), University Medical Centre Ljubljana (UMCL). It was performed in accordance with the Helsinki declaration ethical standards for biomedical studies on human beings on the basis of patient charts held at Clinical Department of Gastroenterology and CIR UMCL. It was approved by Republic of Slovenia National Medical Ethics Committee on the $19^{\text {th }}$ of August 2014 (118/08/14).

\section{Study population and study design}

From all the patients with HCC who had CTPI before treatment with TACE between December 2010 and January 2013 (the total number of patients was 38) only the patients with intermediate stage HCC treated with DEBTACE were selected. Examinations where CTPI analysis could not be performed due to technical reasons (the section of portal vein was not visible on recordings) were excluded from the study. We also excluded the patients whose perfusion parameters were not indicating an active HCC because of previous TACE treatments.

Thus, the final study cohort comprised 18 patients (17 men, 1 woman: mean age, $69 \pm 5.8$ 
years) who all underwent CTPI before treatment with DEBTACE. All patients were examined using a 64-slice dual-source CT (Siemens Medical Systems ${ }^{\circledR}$, Erlangen, Germany) and after the examination data was transferred to outside work station (MultiModality Workplace; Siemens Healthcare). Treatment with DEBTACE was based on the consensus of the Liver Multidisciplinary Team Meeting, held weekly at our institution. All patients underwent at least two sessions of DEBTACE. It was performed in local anesthesia with superselective microcatheter technique with $2.4 \mathrm{~F}$ microcatheter (Progreat ${ }^{\circledR}$, Terumo Europe N.V, Belgium). DEBs with a diameter of 100-300 $\mu \mathrm{m}$ (DC Beads ${ }^{\circledR}$, Terumo Europe N.V, Belgium) were loaded with $50-100 \mathrm{mg}$ of doxorubicin. In patients with multifocal tumors, the position of the microcatheter was changed within the same session if necessary to ensure superselective DEB delivery in each lesion. Radiological follow up was performed every 3 months. Follow up imaging was performed with contrast enhanced four-phase CT or MRI of the liver enhanced with contrast medium specific for the liver. 64- and 16-slice multidetector CT (Siemens Medical Systems ${ }^{\circledR}$, Erlangen, Germany) and 3 T MRI (Siemens Medical Systems ${ }^{\circledR}$, Erlangen, Germany) were used. Treatment was repeated on demand, that is, in patients with residual or recurrent tumors observed by CT or MRI, according to the mRECIST and in agreement with recent expert opinions. Data from patient charts was inserted into clinical protocols. The following data were collected: age at CTPI, sex, clinical status of patient, etiology of liver cirrhosis, stage of liver cirrhosis according to Child-Pugh, size, number and position of lesions, laboratory parameters (blood screen, bilirubin, transaminase, urea, creatinine), portal vein permeability, extrahepatic spread of the disease, perfusion parameters (hepatic blood flow (BF), hepatic blood volume (BV), time to peak (TTP), permeability (PMB), arterial liver perfusion (ALP), portal venous perfusion (PVP) and hepatic perfusion index (HPI)) in target lesion, selectiveness of TACE, the use of microcatheter, the use of ConeBeam CT technology, type and size of embolization particles, the dose of chemotherapeutic (doxorubicin), number of DEBTACE procedures, response to treatment according to MRECIST criteria and survival.

\section{CTPI protocol}

CTPI was performed by using a 64-slice dualsource CT (Siemens Medical Systems ${ }^{\circledR}$, Erlangen,
Germany). The scan region of the tumor was based on the CT scan of the abdomen $(120 \mathrm{kV}, 180 \mathrm{~mA})$ obtained without contrast medium during a breath hold at the end of expiration. The scanned region with CTPI consisted of 4 adjacent $6 \mathrm{~mm}$ thick sections. For lesions larger than $24 \mathrm{~mm}$ in diameter, the levels with the largest tumor diameter were selected. A dynamic study of the selected area was performed in a single breath hold at the end of expiration with the administration of $50 \mathrm{ml}$ non-ionic contrast agent (Visipaque $320^{\circledR}$, GE Healthcare) at a rate of $6 \mathrm{ml} / \mathrm{s}$ via a power injector by using a bolus tracking algorithm through an 18-gauge intravenous cubital cannula. CTPI scanning (100 mA, $80 \mathrm{kV}$, section thickness of $6 \mathrm{~mm}$, rotation time 1 second, matrix $512 \times 512 \mathrm{~mm}$ ) was initiated $6 \mathrm{sec}-$ onds after the injection start, and 4 contiguous sections of tissue were scanned every second for 55 seconds. The contrast agent administration was followed by a power injection of $20 \mathrm{ml}$ of saline (at the same injection rate).

\section{Computed tomographic perfusion analysis}

Quantitative analysis of CTPI data was performed using commercially available software (Syngo Volume Perfusion CT Body; Siemens Healthcare). An integrated motion correction algorithm for anatomic alignment was applied. Volumes of interest were manually drawn around the target lesion, spleen, portal vein and aorta. For better determination of target lesion images of the target lesions in the baseline CT were used. The software then created quantitative maps of perfusion and calculated CTPI parameters and standard deviations. The parameters were calculated on the basis of the method described by Blomley et al. and Tshusima et al. ${ }^{17,21}$ CTPI parameters were calculated in the volume of interest drawn around the borders of the tumor and in the tumor-free parenchyma. Several parameters can be derived from CTPI studies. Hepatic blood flow $(\mathrm{BF})$, representing the flow rate through vasculature; Hepatic blood volume (BV), representing the volume of flowing blood; Time to peak (TTP), defined as the time from arrival of the contrast medium in major arterial vessels to the peak enhancement; Permeability (PMB), representing the total flow from plasma to interstitial space; Arterial liver perfusion (ALP), representing the flow rate through arterial vasculature; Portal venous perfusion (PVP), representing the flow rate through venous vasculature and Hepatic perfusion index (HPI), defined as the ratio 


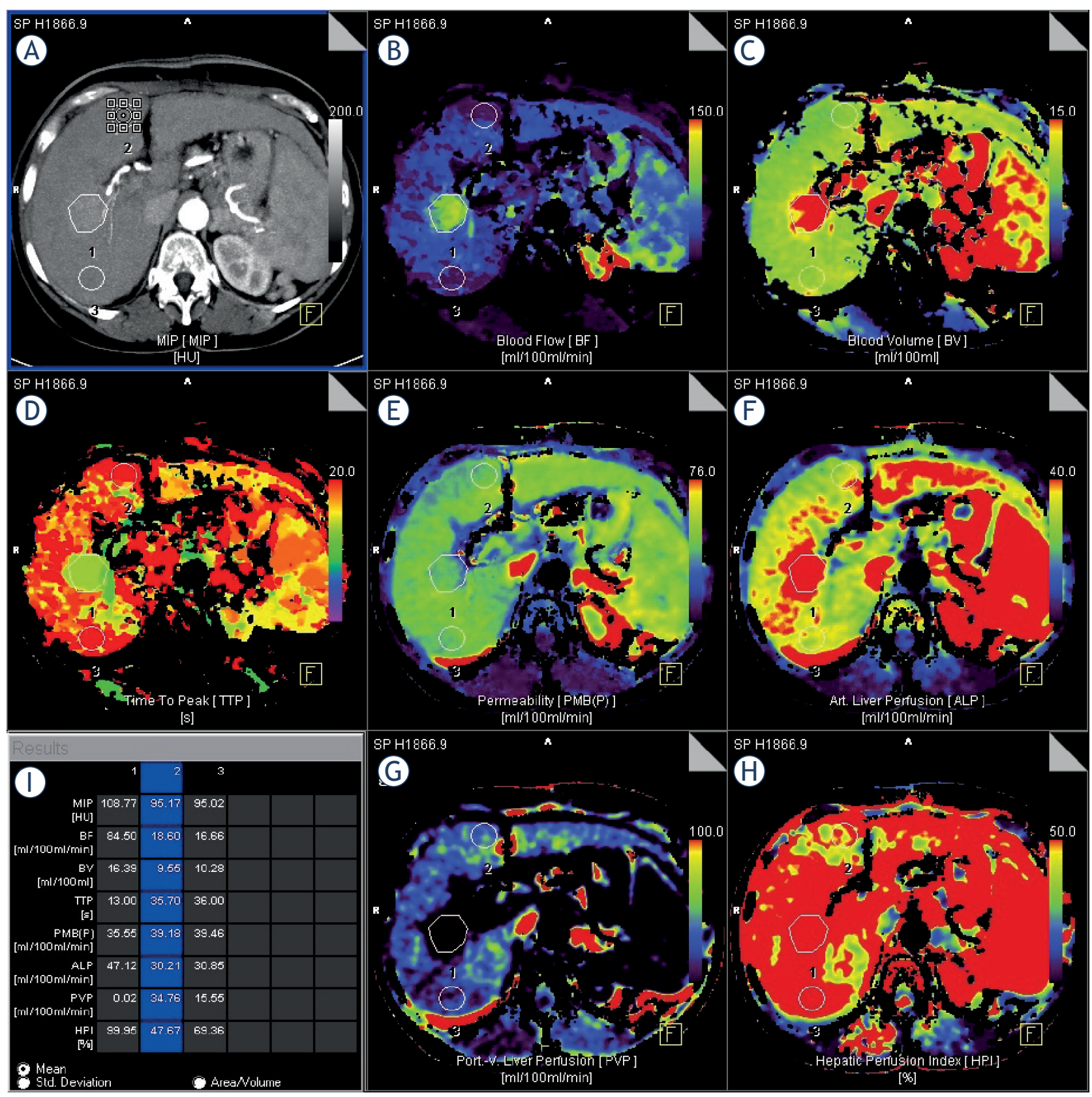

FIGURE 1. Computed Tomographic Perfusion Imaging of the liver. Image of a 65 -year-old woman with hepatocellular carcinoma. (A) HCC in the segment VIII of the liver (1 - volume of interest in the the tumor, 2 - volume of interest in the normal liver parenchyma, 3 - volume of interest in the normal liver parenchyma). (B) Higher BF values in the tumor $(84.50 \mathrm{ml} / 100 \mathrm{ml} / \mathrm{min}$ ) in comparison with normal liver parenchyma (18.60 and $16.66 \mathrm{ml} / 100 \mathrm{ml} / \mathrm{min})$. (C) Higher BV values in the tumor $(16.39 \mathrm{ml} / 100 \mathrm{ml})$ in comparison with the normal liver parenchyma $(9.55$ and 10.28 $\mathrm{ml} / 100 \mathrm{ml})$. (D) Lower TTP values in the the tumor (13.00 s) in comparison with the normal liver parenchyma (35.70 and $36.00 \mathrm{~s})$. (E) Lower PMB values in the tumor $(35.55 \mathrm{ml} / 100 \mathrm{ml} / \mathrm{min}$ ) in comparison with the normal liver parenchyma (39.18 and $39.46 \mathrm{ml} / 100 \mathrm{ml} / \mathrm{min})$. (F) Higher ALP in the tumor $(47.12 \mathrm{ml} / 100 \mathrm{ml} / \mathrm{min})$ in comparison with the normal liver parenchyma $(30.21$ and $30.85 \mathrm{ml} / 100 \mathrm{ml} / \mathrm{min})$. (G) Lower PVP values in the tumor $(0.02 \mathrm{ml} / 100 \mathrm{ml} / \mathrm{min})$ in comparison with the normal liver parenchyma (34.76 and $15.55 \mathrm{ml} / 100 \mathrm{ml} / \mathrm{min})$. (H) Higher HPI values in the tumor $(99.95 \%)$ in comparison with the normal liver parenchyma (47.67 and $69.36 \%)$. (I) Calculation of perfusion parameters.

between arterial liver perfusion and total liver perfusion. Hepatic drawing was done by one reader in the presence of an experienced abdominal radiologist (Figure 1).

\section{Statistical analysis}

Statistical analysis was performed with IBM ${ }^{\circledR}$ SPSS $^{\circledR}$ Statistics 20 (International Business Machines 
Corp., Armonk, New York) for Windows software. Kolmogorov-Smirnov test was used to determine normality of our data. The Student $t$ test for independent samples was used for comparing CTPI parameters between lesions with complete response and those with partial response. The threshold values for CTPI parameters used for survival analysis were established by using receiver operating characteristic (ROC). ROC analysis tested the ability of each CTPI parameter to help identify patients surviving longer than the follow-up period of two years. The point on the ROC curve furthest from the line of no discrimination was considered the optimum threshold value. Survival time was defined as the time between the date of first TACE and the date of death. A patient was considered lost to follow-up for all time points that exceeded the follow-up period for that patient. The KaplanMeier curves were used to illustrate the overall survival rates. Statistical significance was interfered at $p$ less than 0.05. Categorical variables are expressed as frequencies and percentages. Quantitative variables are expressed as means and standard deviations (SD).

\section{Results}

\section{Patient characteristics}

The baseline demographic, clinical, laboratory and tumor staging characteristics of the patients included in the analysis are summarized in Table 1. Patients underwent CTPI $22 \pm 49.7$ days before treatment with DEBTACE. They were treated with a total of 62 DEBTACE procedures. The mean number of procedures per patient was $3.4 \pm 1.5$. Followup imaging was performed $4.9 \pm 3.3$ months after the first DEBTACE.

\section{Computed tomographic perfusion and morphologic treatment response}

We divided our target lesions on the basis of treatment response to DEBTACE determined at the follow-up imaging. Treatment response was described as complete or partial by mRECIST criteria. Lesions with complete response to treatment were in the first group, lesions with partial response in the second group. In the first group there were nine lesions, and in the second there were ten. We compared these groups with the use of Student $t$ test for independent variables. Our results showed no statistically significant difference between our groups (Table 2).
TABLE 1. Baseline characteristics of the patients

\begin{tabular}{|c|c|}
\hline Age [years] & $68.8 \pm 5.8$ \\
\hline $\operatorname{Sex}(M / F), n[\%]$ & $17 / 1[94.4 / 5.6]$ \\
\hline Cirrhosis (yes/no), n [\%] & $16 / 2[88.9 / 11.1]$ \\
\hline $\begin{array}{l}\text { Aetiology of cirrhosis, } n \text { [\%] } \\
\text { Alcohol } \\
\text { HBV } \\
\text { HCV } \\
\text { Other }\end{array}$ & $\begin{array}{c}7[43.8] \\
3[18.8] \\
1[6.3] \\
5[31.3]\end{array}$ \\
\hline Albumin $[\mathrm{g} / \mathrm{l}]$ & $38.3 \pm 5.1$ \\
\hline INR & $1.2 \pm 0.3$ \\
\hline Total bilirubin [mmol/l] & $23.6 \pm 18.8$ \\
\hline $\begin{array}{l}\text { Child-Pugh score (points) } \\
\text { A, n [\%] } \\
B, n[\%]\end{array}$ & $\begin{array}{c}5.7 \pm 0.8 \\
14[77.8] \\
4[22.2]\end{array}$ \\
\hline Creatinine $[\mu \mathrm{mol} / \mathrm{l}]$ & $87.8 \pm 22.8$ \\
\hline AST $[\mu k a t / l]$ & $1.1 \pm 0.9$ \\
\hline ALT [ $\mu \mathrm{kat} / \mathrm{I}]$ & $0.9 \pm 0.8$ \\
\hline yGT [ukat/l] & $1.9 \pm 1.1$ \\
\hline AFP [KIE/l] & $174.5 \pm 279.3$ \\
\hline Portal vein thrombosis (yes/no), n [\%] & $3 / 15$ [16.7/83.3] \\
\hline Bilobar disease, n [\%] & $4[22.2]$ \\
\hline $\begin{array}{l}\text { Unilobar disease, n [\%] } \\
\text { Right lobe, n [\%] } \\
\text { Left lobe, n [\%] }\end{array}$ & $\begin{array}{l}14[77.8] \\
13[92.9] \\
1[7.1]\end{array}$ \\
\hline $\begin{array}{l}\text { Overall number of lesions, } n \\
\text { Average number of nodules per patient }\end{array}$ & $\begin{array}{c}56 \\
3.1 \pm 2.1\end{array}$ \\
\hline Average of HCC nodule diameters [ $\mathrm{cm}]$ & $4.4 \pm 1.8$ \\
\hline
\end{tabular}

AFP = alpha-fetoprotein; $\mathrm{ALT}=$ alanine aminotransferase; $\mathrm{AST}=$ aspartate aminotransferase: $\mathrm{HBV}=$ hepatitis $\mathrm{B}$ virus; $\mathrm{HCV}=$ hepatitis $\mathrm{C}$ virus; $I N R=$ International normalized ratio; $Y G T=$ gamma-glutamyltranspeptidase. International normalized ratio; $Y G T=$ gamma-glutamyltranspeptidase Quantitative variables are expressed as means and standard deviations.
Categorical variables are expressed as frequencies and percentages

\section{Patient outcome}

The follow-up time from the first DEBTACE was on average $24.3 \pm 13.1$ months and 10 patients died in this time. The mean survival time was $25.4 \pm 3.2$ months (95\% CI: 18.7-32.1). One-year and two-year survival was $83.3 \%$ and $50 \%$ respectively. KaplanMeier curves were used to illustrate overall survival rates. Patients were divided into two groups on the basis of threshold values for each CTPI parameter. Patients with a CTPI parameter value lower than the threshold value were placed in the "group 1" and patients with higher CTPI parameter value in "group 2". Threshold values were set at $\mathrm{BF} 50.4 \mathrm{ml} / 100 \mathrm{ml} / \mathrm{min}(88.9 \%$ sensitivity, $66.7 \%$ specificity), BV $13.3 \mathrm{ml} / 100 \mathrm{ml}(88.9 \%$ sensitivity, $55.6 \%$ specificity), TTP 19 s (100\% sensitivity, $44.4 \%$ specificity), PMB $40.2 \mathrm{ml} / 100 \mathrm{ml} / \mathrm{min}(88.9 \%$ 
sensitivity, 44.4\% specificity), ALP $33.1 \mathrm{ml} / 100 \mathrm{ml} /$ $\min (55.6 \%$ sensitivity, $55.6 \%$ specificity), PVP 1.8 $\mathrm{ml} / 100 \mathrm{ml} / \mathrm{min}(88.9 \%$ sensitivity, $33.3 \%$ specificity), HPI $82.7 \%$ (77.8\% sensitivity, $66.7 \%$ specificity). The number of patients in groups varies with different CTPI parameters. Statistically significant differences in mean survival times were seen at CTPI parameters BF, BV and TTP $(p=0.033, p=$ 0.028 in $p=0.015$ respectively) (Table 3, Figure 2). There was no statistically significant difference in mean survival times with other CTPI parameters (PMB $(p=0.079), \operatorname{ALP}(p=0.691), \operatorname{PVP}(p=0.400)$ and HPI $(p=0.244))$ (Table 3).

\section{Discussion}

The BCLC guidelines for the treatment of HCC recommend TACE for patients with intermediatestage HCC. Due to heterogeneity of the patient population tumor response and survival rates are variable. ${ }^{14,5,9-11}$ The overall response rate for TACE treatment is about $50 \%$, with the lowest reported around $15 \%$ and the highest around $85.6 \% .^{1-8}$ Reported 1-, 2- and 3-year survival rates range from $37 \%$ to $91.5 \%, 14 \%$ to $75 \%$ and $58.8 \%$ to $71.4 \%$, respectively. ${ }^{1,3,4}$ Current prognostic factors for determination of treatment response and survival in patients treated with TACE are mainly based on clinical assessment and are included in the BCLC classification. ${ }^{1,13}$ However, the malignant nature of the tumor, as well as its other characteristics, are not considered. Apart from the well-known clinical factors related to tumor stage and liver function, remarkably few data are available upon other measurable prognostic or predictive factors for TACE treatment response and survival of patients with intermediate stage HCC. Thus, careful selection of patients likely to respond and benefit from TACE using a noninvasive imaging biomarker seems important. ${ }^{13,14}$ In the present study, we used pre-treatment CTPI parameters to determine if they could be used as predicting factors for treatment response and prognostic factors for survival.

We were not able to demonstrate a significant correlation between the values of pre-treatment CTPI parameters and the type of response to DEBTACE according to mRECIST criteria, although the mean values of CTPI parameters in the two groups do show some promise for future studies. Target lesions with complete response had lower pre-treatment mean values of BF, BV, ALP and HPI and higher pre-treatment mean values of TTP and PVP than target lesions with partial re-
TABLE 2. CTPI Parameters of target lesions before treatment with TACE

\begin{tabular}{lccc} 
& $\begin{array}{c}\text { Complete response } \\
(\mathrm{n}=\mathbf{9})\end{array}$ & $\begin{array}{c}\text { Partial response } \\
(\mathrm{n}=10)\end{array}$ & $\boldsymbol{P}$ \\
\hline $\mathrm{BF}[\mathrm{ml} / 100 \mathrm{ml} / \mathrm{min}]$ & $36.3 \pm 23.2$ & $51 \pm 31.6$ & 0.271 \\
$\mathrm{BV}[\mathrm{ml} / 100 \mathrm{ml}]$ & $11.6 \pm 5$ & $14.4 \pm 4.8$ & 0.240 \\
TTP $[\mathrm{s}]$ & $26.3 \pm 8.3$ & $24 \pm 7.8$ & 0.551 \\
PMB $[\mathrm{ml} / 100 \mathrm{ml} / \mathrm{min}]$ & $37.3 \pm 19.3$ & $33.6 \pm 10.9$ & 0.616 \\
ALP $[\mathrm{ml} / 100 \mathrm{ml} / \mathrm{min}]$ & $38.7 \pm 22.2$ & $49 \pm 28.9$ & 0.400 \\
PVP $[\mathrm{ml} / 100 \mathrm{ml} / \mathrm{min}]$ & $20.8 \pm 22.7$ & $13 \pm 17$ & 0.404 \\
HPI $[\%]$ & $65.1 \pm 30.7$ & $78.6 \pm 27.4$ & 0.322 \\
\hline
\end{tabular}

$\mathrm{ALP}=$ arterial liver perfusion; $\mathrm{BF}=$ hepatic blood flow; $\mathrm{BV}=$ hepatic blood volume; $\mathrm{HPI}=$ hepatic perfusion index: $p=$ statistical significance: $P M B=$ permeability; $P V P=$ portal vein perfusion; TTP = time to peak. Quantitative variables are expressed as means with standard deviation.

TABLE 3. Patients' survival. Group 1 - patients with the value of CTPI parameter lower than the threshold value, group 2 - patients with the value of CTPI parameter higher than the threshold value

\begin{tabular}{ccccc}
\hline & Threshold value & $\begin{array}{c}\text { Group 1 } \\
\text { mean survival } \\
\text { [months] }\end{array}$ & $\begin{array}{c}\text { Group 2 } \\
\text { mean survival } \\
\text { [months] }\end{array}$ & $\boldsymbol{P}$ \\
\hline $\mathrm{BF}$ & $50.4 \mathrm{ml} / 100 \mathrm{ml} / \mathrm{min}$ & $35.6 \pm 5$ & $18.8 \pm 2.7$ & 0.033 \\
$\mathrm{BV}$ & $13.3 \mathrm{ml} / 100 \mathrm{ml}$ & $35.2 \pm 4.3$ & $18.8 \pm 4.1$ & 0.028 \\
$\mathrm{TTP}$ & $19 \mathrm{~s}$ & $16.4 \pm 0.8$ & $33.2 \pm 4.7$ & 0.015 \\
$\mathrm{PMB}$ & $40.2 \mathrm{ml} / 100 \mathrm{ml} / \mathrm{min}$ & $33.8 \pm 4.2$ & $15.9 \pm 5.4$ & 0.079 \\
$\mathrm{ALP}$ & $33.1 \mathrm{ml} / 100 \mathrm{ml} / \mathrm{min}$ & $30.2 \pm 6.6$ & $27.1 \pm 3.8$ & 0.691 \\
$\mathrm{PVP}$ & $1.8 \mathrm{ml} / 100 \mathrm{ml} / \mathrm{min}$ & $23.5 \pm 5.5$ & $30.8 \pm 4.7$ & 0.400 \\
$\mathrm{HPI}$ & $82.7 \%$ & $32.8 \pm 6$ & $24 \pm 3.8$ & 0.244 \\
\hline
\end{tabular}

$\mathrm{ALP}=$ arterial liver perfusion; $\mathrm{BF}=$ hepatic blood flow; $\mathrm{BV}=$ hepatic blood volume, $\mathrm{HPI}=$ hepatic perfusion index; $\mathrm{p}=$ statistical significance in mean survival between group 1 and group $2 ; \mathrm{PMB}=$ permeability; PVP = portal vein perfusion, TTP = time to peak, Quantitative variables are expressed as means with standard deviation.

sponse, although these differences were not statistically significant.

When comparing the overall survival of patients, we were able to demonstrate a correlation between pre-treatment CTPI parameter values and overall survival in patients with intermediate stage HCC. To our knowledge, this is the first time this finding has been reported in patients with HCC undergoing TACE. Patients with pre-treatment CTPI parameter BF lower than $50.4 \mathrm{ml} / 100 \mathrm{ml} /$ min, BV lower than $13.3 \mathrm{ml} / 100 \mathrm{ml}$ and TTP longer than $19 \mathrm{~s}$ had significantly longer survival (35.6 vs. 18.8 months, 35.2 vs. 18.8 months and 33.2 vs. 16.4 months, respectively). Although we could not demonstrate significant difference in mean survival values between groups when testing other CTPI parameters, the results show some promise for future studies. Survival was longer in the group 

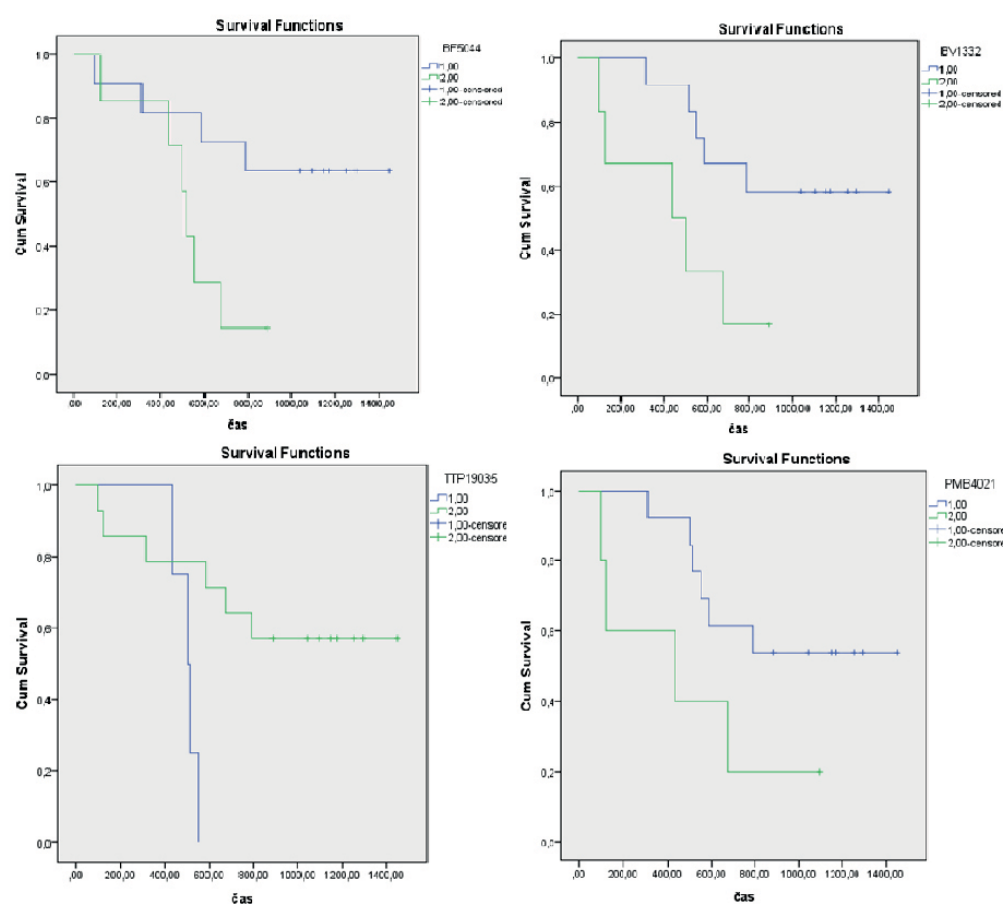

FIGURE 2. Kaplan-Meier survival curves. Patients with BF value lower than 50.4 $\mathrm{ml} / 100 \mathrm{ml} / \mathrm{min}$, BV lower than $13.3 \mathrm{ml} / 100 \mathrm{ml}$, TTP longer than $19 \mathrm{~s}$ have statistically significant longer survival $(p=0.033, p=0.028, p=0.015)$. Čas $=$ Time in days. Blue line - Group 1, Green line - Group 2.

of patients with values of pre-treatment CTPI parameter PMB lower than $40.2 \mathrm{ml} / 100 \mathrm{ml} / \mathrm{min}$, ALP lower than $33.1 \mathrm{ml} / 100 \mathrm{ml} / \mathrm{min}$, PVP values higher than $1,8 \mathrm{ml} / 100 \mathrm{ml} / \mathrm{min}$, and HPI values lower than $82,7 \%$.

CTPI of the liver provides functional information about the microcirculation of normal parenchyma and focal neoplastic lesions of the liver and has already been studied as a possible prognostic biomarker in other malignancies. ${ }^{16-18}$ Results of these studies show that response to treatment with chemotherapy, radiotherapy and anti-angiogenic drugs is better when the values of $\mathrm{BF}$ and $\mathrm{BV}$ are high. ${ }^{32-37} \mathrm{~A}$ possible explanation for this is that well-perfused tumors allow better delivery of chemotherapy. They may also have better oxygenation and thus potentially have greater radiosensitivity. ${ }^{38}$ Similar results were found by Morsbach et al. ${ }^{16}$ They were able to demonstrate that the ALP of liver metastases before treatment with TARE enables the prediction of morphologic response and survival to therapy. Responders to therapy regarding tumor size reduction showed significantly higher ALP values as compared with those not responding to TARE. Differences in the therapeutic option used in our study and the fact that HCC is a highly vascular tumor with different degree of tumor arterial perfusion, different pathological grade and clinical behavior during hepatocarcinogenesis might well account for differences between our results and the results of these studies. However, results of our study are similar to those reported by Jiang et al. ${ }^{39}$ and Petralia et al..$^{40}$ in trials of 23 and 12 patients with advanced HCC treated with a combination of anti-angiogenic treatment and chemotherapy. They reported that tumors with poor prognosis tend to show higher baseline $\mathrm{BF}$ and $\mathrm{BV}$, suggesting higher vascularity along with extensive intratumoral arteriovenous shunts. Results of our study also show similarity with a study conducted by Michielsen et al. ${ }^{41}$ in patients undergoing TACE for inoperable HCC. Patients with higher vascularized lesions had shorter progression-free survival after TACE, indicating higher malignancy potential of highly vascularized tumors.

HCC is a highly vascular tumor and the source of intranodular blood supply changes during carcinogenesis. Early stage HCC still has some supply from the portal vein, and when it reaches the stage of moderately differentiated HCC, it receives all the arterial blood supply from abnormal arteries formed during carcinogenesis. For this reason, the arterial blood supply tends to increase during hepatocarcinogenesis. ${ }^{42}$ Perfusion imaging techniques would be ideal for the prediction of the pathological grade and clinical behavior of HCC, but literature data on this topic is relatively poor. Yang HF et al. ${ }^{15}$ investigated the value of CTPI for assessment of angiogenesis in liver cancer and concluded that BF and ALP might be useful parameters in assessing angiogenesis in liver cancer. The values of these two parameters correlated with microvascular density. And since the degree of tumor perfusion is potentially associated with tumor aggressiveness our hypothesis was that patients with lower values of BF and ALP in the tumor should have a better response to treatment and longer overall survival than those with high values of these perfusion parameters. ${ }^{18}$ Furthermore, treatment response with necrosis is based on local chemoembolization of feeding vessels, and there could be a correlation between the embolization of all feeding vessels and the success of DEBTACE. On the other hand Ippolito et al. ${ }^{43}$ did not report any significant correlation between CTPI parameters and pathological grade and Sahani et al..$^{44}$ found that well-differentiated HCC had significantly higher CTPI parameter values (higher BF, BV and PMB) than moderately and poorly differentiated HCC. Sahani concluded that relatively larger tumor diameter (mean > 
$9 \mathrm{~cm}$ ) and the presence of tumor necrosis in the high-grade tumor group could account for these observations. However, in our study, we did not include any patients with a large central necrosis that would produce such results.

The results from our study using CTPI, representing an objective, quantitative imaging tool, showed a predictive value of pre-treatment $\mathrm{BF}, \mathrm{BV}$ and TTP of HCC for overall survival of patients treated with DEBTACE. As previously discussed, these parameters could be used as predictive biomarkers. Higher values of BF, BV and on the other hand lower values of TTP could represent a highly vascularized tumor. ${ }^{15,20,29-31,41,42,45}$ Patients with such tumors may benefit from treatments that work better with high CTPI parameter values, such as TARE or anti-angiogenic therapies. ${ }^{13,33,34,46}$

When working with CTPI the radiation dose is an important aspect that needs to be considered. It is normally equal or higher to that of multiphase $\mathrm{CT}$ acquisitions. The radiation dose is estimated to be from 7.3 to $30.6 \mathrm{mSv}$ and depends on the technology used. It is especially important to consider this with oncologic patients that undergo several CT scans before and after treatment. ${ }^{47}$

Our study has some limitations. First, our study is a retrospective study. Therefore, we had to work with the available data, instead of carefully planning the timing of procedures. Second, we included a limited number of patients. Future studies should aim at the inclusion of a larger group of patients, preferably in a multicentric fashion. Third, histopathologic correlation with CT or MR imaging regarding tumor necrosis after treatment with DEBTACE was not performed since previous reports already showed good correlation between the percentage of tumor necrosis obtained at the histopathologic examination and the tumor enhancement assessed with imaging. Fourth, the reading of CTPI was only done once, so we had no data to compare unbiased inter-reader variability. Fifth, we did not take into account different determinants of therapeutic response to DEBTACE, such as liver cirrhosis, gender, age, number and size of tumors, invasion of the portal vein, dosage of chemotherapeutic, but rather only correlated CTPI parameters with different treatment responses to DEBTACE. Finally, the results of this study are not directly transferable when using other software. The difference in values of perfusion parameters could be up to $46 \%$ when using different software. ${ }^{48}$

In conclusion, our results suggest that pre-treatment CTPI parameters BF, BV and TTP measured in HCC are related to overall survival of patients treated with DEBTACE. Thus, CTPI has the potential to become a new imaging biomarker for selecting patients who will benefit from treatment with DEBTACE. Our study and most previous studies investigating the CTPI parameters were based on retrospectively acquired data, further large-scale prospective clinical trials are required.

\section{References}

1. European Association for the Study of the Liver, European Organisation for Research and Treatement of Cancer. EASL-EORTC clinical practice guidelines: management of hepatocellular carcinoma. J Hepatol 2012; 56: 908-43. doi: 10.1016/j.jhep.2011.12.001

2. Lammer J, Malagari K, Vogl T,Pilleul F, Denys A, Watkinson A, et al. Prospective randomized study of doxorubicin-eluting-bead embolization in the treatment of hepatocellular carcinoma: results of the PRECISION V study. Cardiovasc Intervent Radiol 2010; 33: 41-52. doi: 10.1007/s00270009-9711-7

3. Dhanasekaran R, Kooby DA, Staley CA, Kauh JS, Khanna V, Kim HS, et al. Comparison of conventional transarterial chemoembolization (TACE) and chemoembolization with doxorubicin drug eluting beads (DEB) for unresectable hepatocelluar carcinoma (HCC). J Surg Oncol 2010; 101: 476-80. doi: $10.1002 /$ jso. 21522

4. Malagari K, Pomoni M, Moschouris H,Bouma E, Koskinas J, Stefaniotou A et al. Chemoembolization with doxorubicin-eluting beads for unresectable hepatocellular carcinoma: five-year survival analysis. Cardiovasc Intervent Radiol 2012; 35: 1119-28.

5. Varela M, Real MI, Burrel M, Forner A, Sala M, Brunet $M$, et al. Chemoembolization of hepatocellular carcinoma with drug eluting beads: efficacy and doxorubicin pharmacokinetics. J Hepatol 2007; 46: 474-81.

6. Popovic P, Stabuc B, Jansa R, Garbajs M. Survival of patients with intermediate stage hepatocellular carcinoma treated with superselective transarterial chemoembolization using doxorubicin-loaded DC Bead under conebeam computed tomography control. Radiol Oncol 2016; 50: 418-26. doi: 10.1515/raon-2015-0045

7. Kettenbach J, Stadler A, Katzler IV, Schernthaner R, Blum M, Lammer J, et al. Drug-loaded microspheres for the treatment of liver cancer: review of current results. Cardiovasc Intervent Radiol 2008; 31: 468-76. doi: 10.1007/ s00270-007-9280-6

8. Malgari K, Chatzimichael K, Alexopöulou E, Kelekis A, Hall B, Dourakis S, et al. Transarterial chemoembolisation of unresectable hepatocelular carcinoma with drug eluting beads: results of an open-label study of 62 patients. Cardiovasc Interv Radiol 2008; 31: 269-80.

9. Lencioni R, Llovet JM. Modified RECIST (mRECIST) assessment for hepatocellular carcinoma. Sem Liver Disease 2010; 30: 52-60. doi: 10.1055/s0030-1247132

10. Llovet JM, Bruix J. Systematic review of randomized trials for unresectable hepatocellular carcinoma: Chemoembolization improves survival. Hepatology 2003; 37: 429-42.

11. Takayasu K, Arii S, Ikai I, Omata M, Okita K, Ichida T, et al. Prospective cohort study of transarterial chemoembolization for unresectable hepatocellular carcinoma in 8510 patients. Gastroenterology 2006; 131: 461-9.

12. Burrel M, Reig M, Forner A, Barrufet $M$, de Lope $C R$, Tremosini $S$, et al. Survival of patients with hepatocellular carcinoma treated by transarterial chemoembolisation (TACE) using Drug Eluting Beads. Implications for clinical practice and trial design. J Hepatol 2012; 56: 1330-5. doi: 10.1016/j. jhep.2012.01.008

13. Fatourou EM, Tsochatzis EA. ART and science in using transarterial chemoembolization for retreating patients with hepatocellular carcinoma. Hepatobiliary Surg Nutr 2014; 3: 415-8. doi: 10.3978/j. issn.2304-3881.2014.07.01

14. Tsochatzis EA, Fatourou E, O’Beirne J, Meyer T, Burroughs AK. Transarterial chemoembolization and bland embolization for hepatocellular carcinoma. World J Gastroenterol 2014; 20: 3069-77. doi: 10.3748/wjg.v20.i12.3069 
15. Yang HF, Du Y, Ni JX, Zhou XP, Li JD, Zhang Q, et al. Perfusion computed tomography evaluation of angiogenesis in liver cancer. Eur Radiol 2010; 20 1424-30. doi: 10.1007/s00330-009-1693-y

16. Morsbach F, Pfammatter T, Reiner CS, Fischer MA, Sah BR, Winklhofer S, et al. Computed tomographic perfusion imaging for the prediction of response and survival to transarterial radioembolization of liver metastases. Invest Radiol 2013; 48: 787-94. doi: 10.1097/RLI.0b013e31829810f7

17. Blomley MJ, Coulden R, Dawson P, Kormano M, Donlan P, Bufkin C, et al. Liver perfusion studied with ultrafast CT. J Comput Assist Tomogr 1995; 19: 424-33.

18. Garcia-Figueiras R, Goh VJ, Padhani AR, Baleato-González S, Garrido M León L, et al. Ct perfusion in oncologic imaging: A useful tool? AJR Am J Roentgenol 2013; 200: 8-19. doi: 10.2214/AJR.11.8476

19. Avsenik J, Bisdas S, Popovic KS. Blood-brain barrier permeability imagin using perfusion computed tomography. Radiol Oncol 2015; 49: 107-14. doi: 10.2478/raon-2014-0029

20. Goh V, Halligan S, Daley F, Wellsted DM, Guenther T, Bartram Cl. Colorectal tumor vascularity: quantitative assessment with multidetector CT--do tumor perfusion measurements reflect angiogenesis? Radiology 2009; 249: 510-7. doi: 10.1148 /radiol.2492071365

21. Tsushima Y, Funabasama S, Aoki J,Sanada S, Endo K. Quantitative perfusion map of malignant liver tumors, created from dynamic computed tomography data. Acad Radiol 2004; 11: 215-23.

22. Yang L, Zhang XM, Tan BX, Liu M, Dong GL, Zhai ZH. Computed tomographic perfusion imaging for the therapeutic response of chemoembolization for hepatocellular carcinoma. J Comput Assist Tomogr 2012; 36: 226-30. doi: 10.1097/RCT.0b013e318245c23c

23. Chen G, Ma DQ, He W, Zhang BF, Zhao LQ. Computed tomography perfusion in evaluating the therapeutic effect of transarterial chemoembolization for hepatocellular carcinoma. World J Gastroenterol 2008; 14: 5738-43.

24. Sahani D, Holalkere DS, Mueller PR, Zhu AX. Advanced hepatocellular carcinoma: CT perfusion of liver and tumor tissue-initial experience. Radiology 2007; 243: 736-43.

25. Zhou ZF, Huang HL, Xu B, et al. Clinic application with MSCT perfusion in liver tumor. Linchuang Fangshexue Zazhi 2006; 25: 233-7.

26. Komemushi A, Tanigawa N, Kojima H, Kariya S, Sawada S. CT perfusion of the liver during selective hepatic arteriography: pure arterial blood perfusion of liver tumor and parenchyma. Radiat Med 2003; 21: 246-51.

27. Ebos JM, Kerbel RS. Antiangiogenic therapy: impact on invasion, disease progression, and metastasis. Nat Rev Clin Oncol 2011; 8: 210-21. doi: 10.1038/nrclinonc.2011.21

28. De Robertis R, Tinazzi Martini P, Demozzi E, Puntel G, Ortolani S, Cingarlin $S$, et al. Prognostication and response assessment in liver and pancreatic tumors: the new imaging. World J Gastroenterol 2015; 21: 6794-808. doi: 10.3748/wjg.v21.i22.6794

29. Ash L, Teknos TN, Gandhi D, Patel S, Mukherji SK. Head and neck squamous cell carcinoma: CT perfusion can help noninvasively predict intratumoral microvessel density. Radiology 2009; 251: 422-8. doi: 10.1148/ radiol. 2512080743

30. Chen $Y$, Zhang J, Dai J, Feng $X$, Lu H, Zhou C. Angiogenesis of renal cell carcinoma: perfusion CT findings. Abdom Imaging 2010; 35: 622-8. doi: 10.1007/s00261-009-9565-0

31. D'Assignies G, Couvelard A, Bahrami S, Vullierme MP, Hammel P, Hentic O, et al. Pancreatic endocrine tumors: tumor blood flow assessed with perfusion CT reflects angiogenesis and correlates with prognostic factors. Radiology 2009; 250: 407-16. doi: 10.1148/radiol.2501080291

32. Fournier LS, Oudard S, Thiam R,Trinquart L, Banu E, Medioni J, et al. Metastatic renal carcinoma: evaluation of anti-angiogenic therapy with dynamic contrast enhanced CT. Radiology 2010; 256: 511-8. doi: 10.1148/ radiol.10091362

33. Bellomi M, Petralia G, Sonzogni A, Zampino MG, Rocca A. CT perfusion for the monitoring of neo-adjuvant chemoradiation therapy in rectal carcinoma. Radiology 2007; 244: 486-93.
34. Han KS, Jung DC, Choi $\mathrm{HJ}$, Jeong MS, Cho KS, Joung JY, et al Pretreatment assesment of tumor enhancement on contrast-enhanced computed tomography as a potential predictor of treatment outcome in metastatic renal cell carcinoma patients receiving antiangiogenic therapy. Cancer 2010; 116: 2332-42. doi: 10.1002/cncr.25019

35. Bisdas S, Surlan-Popovic K, Didanovic V, VogI TJ. Functional CT of squamous cell carcinoma in the head and neck: repeatability of tumor and muscle quantitative measurements, inter- and intra-observer agreement. Eur Radiol 2008; 18: 2241-5. doi: 10.1007/s00330-008-0990-1

36. Gandhi D, Chepeha DB, Miller T, Carlos RC, Bradford CR, Karamchandani R, et al. Correlation between initial and early follow-up CT perfusion parameters with endoscopic tumor response in patients with advanced squamous cell carcinomas of the oropharynx treated with organ-preservation therapy. AJNR Am J Neuroradiol 2006; 27: 101-6.

37. Surlan-Popovic K, Bisdas S, Rumboldt Z, Koh TS, Strojan P. Changes in perfusion CT of advanced squamous cell carcinoma of the head and neck treated during the course of concomitant chemoradiotherapy. AJNR Am J Neuroradiol 2010; 31: 570-5. doi: 10.3174/ajnr.A1859

38. Wang J, Wu N, Cham MD, Song Y. Tumor response in patients with advanced non-small cell lung cancer: perfusion CT evaluation of chemotherapy and radiation therapy. AJR 2009; 193: 1090-6. doi: 10.2214/AJR.08.1367

39. Jiang T, Kambadakone A, Kulkarni NM, Zhu AX, Sahani DV. Monitoring response to antiangiogenic treatment and predicting outcomes in advanced hepatocellular carcinoma using image biomarkers, CT perfusion, tumor density, and tumor size (RECIST). Invest Radiol 2012; 47: 11-7. doi: 10.1097/ RLI.0b013e3182199bb5

40. Petralia G, Fazio N, Bonello L, D’Andrea G, Radice D, Bellomi M. Perfusion computed tomography in patients with hepatocellular carcinoma treated with thalidomide: initial experience. J Comput Assist Tomogr 2011; 35: 195-201. doi: 10.1097/RCT.0b013e31820ccf51

41. Michielsen K, De Keyzer F, Verslype C, Dymarkowski S, van Malenstein $H$, Oyen R, et al. Pretreatment DCE-MRI for prediction of PFS in patients with inoperable HCC treated with TACE. Cancer Imaging 2011; 11: 114.

42. Visualization of multistep hepatocarcinogenesis using various imaging biomarkers [internet]. ECR 2014. C-0120. Retrieved from: http://posterng. netkey.at/esr/viewing/index.php?module=viewing_poster\&task=viewsecti on\&pi=119549\&ti=394293\&searchkey=

43. Ippolito D, Capraro C, Casiraghi A, Cestari C, Sironi S. Quantitative assessment of tumour associated neovascularisation in patients with liver cirrhosis and hepatocellular carcinoma: role of dynamic-CT perfusion imaging. Eur Radiol 2012; 22: 803-11. doi: 10.1007/s00330-011-2307-z

44. Sahani DV, Holalkere NS, Mueller PR, Zhu AX. Advanced hepatocellular carcinoma: CT perfusion of liver and tumor tissue--initial experience. Radiology 2007; 243: 736-43.

45. Frampas $E$, Lassau $N$, Zappa $M$, Vullierme MP, Koscielny $S$, Vilgrain V. Advanced hepatocellular carcinoma: early evaluation of response to targeted therapy and prognostic value of perfusion $\mathrm{CT}$ and dynamic contrast enhanced-ultrasound. Preliminary results. Eur J Radiol 2013; 82: 205-11. doi: 10.1016/j.ejrad.2012.12.004

46. Schmitz S, Rommel D, Michoux N, Lhommel R, Hanin FX, Duprez T, et al. Dynamic contrast-enhanced computed tomography to assess early activity of cetuximab in squamous cell carcinoma of the head and neck. Radiol Oncol 2015; 49: 17-25. doi: 10.2478/raon-2014-0030

47. Kim SH, Kamaya A, Willmann JK. CT perfusion of the liver: principles and applications in oncology. Radiology 2014; 272: 322-44. doi: 10.1148/ radiol.14130091

48. Mazzei MA, Preda L, Cianfoni A, Volterrani L. CT Perfusion: Technical developments and current and future applications. Biomed Res Int 2015; 2015: 397521. doi: 10.1155/2015/397521 